\title{
Preoperative MRI findings and functional outcome after selective dorsal rhizotomy in children with bilateral spasticity
}

\author{
Sebastian Grunt • Jules G. Becher • Petra van Schie • \\ Willem J. R. van Ouwerkerk • Mazarin Ahmadi • \\ R. Jeroen Vermeulen
}

Received: 30 July 2009 /Published online: 13 October 2009

(C) The Author(s) 2009. This article is published with open access at Springerlink.com

\begin{abstract}
Purpose To identify MRI characteristics that may predict the functional effect of selective dorsal rhizotomy (SDR) in children with bilateral spastic paresis.

Methods We performed SDR in a group of 36 patients. The gross motor functioning measure-66 (GMFM-66) was applied before and after SDR. Available cerebral MRIs were retrospectively classified into three diagnostic groups: periventricular leucomalacia (PVL; $n=10$ ), hydrocephalus $(n=2)$, and normal $(n=6)$. In patients with PVL, we scored the severity of the MR abnormalities. We compared the changes in the GMFM-66 after SDR in the diagnostic groups. In patients with PVL, we correlated the severity of the MR abnormalities with the changes in the GMFM-66.
\end{abstract}

This study was supported by the Phelps Foundation for Spasticity (Phelps Stichting voor Spastici, project number 1996.044), The Netherlands. During his work at this study, Sebastian Grunt was supported by grants from the Anna Müller-Grocholski Foundation, Zürich, Switzerland and the Swiss Foundation for Children with Cerebral Palsy, Berne, Switzerland.

S. Grunt · J. G. Becher

Department of Rehabilitation Medicine,

VU University Medical Center,

Amsterdam, The Netherlands

P. van Schie

Department of Physical Therapy,

VU University Medical Center,

Amsterdam, The Netherlands

W. J. R. van Ouwerkerk

Department of Neurosurgery,

VU University Medical Center,

Amsterdam, The Netherlands
Results The mean follow-up period was 5 years and 4 months (range, 1 year and 1 month to 9 years). The best improvement in gross motor function was observed in patients with normal MRI, and the slightest improvement was observed in patients with hydrocephalus. The severity of the PVL did correlate with the GMFM-66 score before SDR but not with the functional effect of SDR.

Conclusion We conclude that with respect to gross motor skills, the improvements after SDR are good in patients with no MRI abnormalities. In the patients with hydrocephalus, the improvements after SDR were insignificant. In patients with PVL, the improvements were intermediate and did not correlate with the degree of PVL.
M. Ahmadi

Department of Radiology,

VU University Medical Center,

Amsterdam, The Netherlands

R. J. Vermeulen $(\square)$

Department of Paediatric Neurology,

VU University Medical Center,

Neuroscience Campus Amsterdam, De Boelelaan 1117,

P.O. Box 7057, 1007 Amsterdam, The Netherlands

e-mail: rj.vermeulen@vumc.nl

Present Address:

S. Grunt

Department of Paediatric Neurology,

University Children's Hospital,

Inselspital, Berne, Switzerland 
Keywords Rhizotomy · Spasticity · Neuroimaging · Hydrocephalus $\cdot$ PVL

\section{Introduction}

Spasticity is defined as a velocity-dependent increase in the tonic stretch response with excessive tendon jerk reflexes [1] and is caused by the reduction of inhibitory impulses on lower motor neurons. Spasticity can cause pain, muscle shortening, and orthopedic malformations, and it can severely interfere with functional abilities and gait pattern. Cerebral palsy (CP) is the most frequent cause of spasticity in children. Cerebral palsy is a group of disorders of movement and posture due to a nonprogressive lesion of the developing brain [2]. As a consequence of this definition, its causes are diverse.

Different treatment modalities are used to treat spasticity in children. Selective dorsal rhizotomy (SDR) is a neurosurgical treatment that is mainly performed at lumbar level in patients with bilateral spastic paresis. By incomplete transection of the (sensory) posterior lumbosacral rootlets, SDR reduces the excitatory input from the lower limbs that enters the spinal cord. In children with spastic CP, SDR leads to a more normal gait pattern [3-6], better performance of the activities of daily life [7, 8], and improvement in gross motor function [6-13]. Data on functional outcome after SDR in patients with other conditions than spastic CP are limited, though promising [14]. Detailed information about the clinical characteristics of the selected children, other than spasticity alone, is often lacking.

Medical history and clinical examination does not always provide sufficient evidence to establish the diagnosis of the underlying disorder in patients with CP. The Quality Standards Subcommittee of the American Academy of Neurology and the Practice Committee of the Child Neurology Society both advise magnetic resonance imaging (MRI) of the brain for all CP patients [15]. In patients with bilateral spastic CP, the most common MRI abnormality is periventricular leucomalacia (PVL), which is characterized by a damage of the periventricular white matter [16-19]. Gray matter lesions, early developmental abnormalities of the central nervous system, and abnormalities of the cerebrospinal fluid space, such as hydrocephalus, are less commonly found [17-19], and in some children with bilateral spastic CP no abnormalities are found with MRI [16-19]. In patients with normal MRI findings and bilateral spastic paresis, genetic causes or spinal cord involvement should be considered.

The goal of this study was to identify possible relationships between the MRI findings with the level of gross motor function of the patient before SDR and the change in functioning after SDR. For this purpose, we retrospectively analyzed the MRIs of the patients who underwent SDR in our clinic.

\section{Methods and materials}

Subjects

This study was part of the project: "Investigation of longterm effects of SDR in children with spastic diplegia" and was approved by the medical ethical committee of the VU University Medical Center, Amsterdam, The Netherlands (project number 2006/105). Informed consent was given by the parents of all participants. The study population consisted of all the patients who underwent SDR in our clinic between January 1998 and December 2007. The first nine patients have been described in a previous report [8]. The patients were selected for SDR according to the criteria shown in Table 1. In our previous study, we only included patients with bilateral spastic CP and documented PVL [8]. In the present study, we included patients with nonprogressive spasticity due to different diagnoses. In our analysis, we included data on patients who underwent pre- and postoperative gross motor function measure (GMFM-66) analysis with a follow-up period of at least 12 months and of whom MRI was available for review.

\section{Procedure}

Selective dorsal rhizotomy was performed by the same neurosurgeon (WVO) in all children. Dorsal roots L2-S1 were exposed and separated into different rootlets after laminotomy L2-L5 and opening of the dura. Transection of

Table 1 Selection criteria for selective dorsal rhizotomy in the VU University Medical Center

Criteria for selective dorsal rhizotomy

1.) Bilateral spasticity of the lower extremities interfering with walking performance

2.) Presence of spasticity (defined as velocity-dependent resistance to passive stretch) in at least six muscle groups of the lower limbs

3.) Sufficient force in the quadriceps femoris muscle (squatting at least seven times) and the hip extensors (kneel with extended hips, support for balance allowed)

4.) Absence of structural orthopedic deformities or contractures at hip, knee, or ankle

5.) Presence of moderate to good selective motor control in the lower limbs

6.) Gross motor function classification system (GMFCS) level I, II, or III

7.) Good support from parents and rehabilitation setting 
the rootlets was performed after electro-stimulation, according to palpable muscle contraction and EMG response. At most, $50 \%$ of the rootlets were transected on one level. To prevent sexual and bladder disturbances, rootlets/fascicles showing electrical response after stimulation of the penis/ the clitoris were spared. Postoperative rehabilitation included intensive physical therapy for 12 months.

\section{Neuroimaging}

The MRIs were assessed at two different points in time by two investigators - one neuropediatrician ( 8 years of experience in the assessment of MR neuroimaging; RJV) and one pediatrician with specialization in pediatric neurorehabilitation ( 2 years of experience in the assessment of MR neuroimaging; SG). Imaging was classified into three diagnostic groups according to the following criteria: periventricular leucomalacia (PVL; increased signal intensity of the periventricular white matter in $\mathrm{T} 2$ weighted imaging and/or FLAIR; other abnormalities optional); hydrocephalus (signs of ventricular dilatation and increased intracranial pressure); normal MRI (see Fig. 1a-i). In one patient, the MR abnormalities could not be classified into one of the three diagnostic groups and he was excluded from further data analysis (patient number 19, Table 2; his MRI showed delayed myelinisation and slightly enlarged ventricular size but no other white matter abnormalities and there were no signs of increased intracranial pressure). In the patients with PVL, we graded the severity of their MRI abnormalities based on the work of Cioni et al. [20]. The following items were assessed: ventricular size, evidence and extension of white matter signal intensity, evidence and extension of white matter loss, thinning of the corpus callosum, dimension (size) of subarachnoidal space, evidence and size of cysts, and presence of gray matter abnormalities. We also investigated whether white matter loss was occipitally and/or frontally present. The items were scored on a three-point scale, with a score of three indicating the most severe MRI abnormalities. The scores were summed to obtain a total score for each child (minimal score, 7 and maximal score, 21). Intra- and interobserver agreement was assessed for all items. If the two investigators did not agree, the classification and/or scoring were determined by a consensus.

\section{Outcome measure}

All patients had a detailed pre- and postoperative clinical evaluation, including spasticity assessment, range of motion of single joints, gait analysis, and the GMFM. In this study, we only report the results of the GMFM. The GMFM is a criterion-referenced observational measure that was developed to assess children with CP. The validity, reliability, and responsiveness of the GMFM have been demonstrated in a population of patients similar to the participants in the present study [21]. For our data analysis, we used the GMFM-66 version, which assesses 66 items covering five gross motor dimensions (lying and rolling/crawling and kneeling/standing and walking/running/jumping) and is elaborated to a numerical scale ranging from 0 to 100 .

As outcome parameters we used the mean of all postoperative GMFM-66 scores from 1 year after surgery. The changes after SDR were expressed as the difference between GMFM-66 score and the preoperative GMFM-66 score (Delta-GMFM-66).

\section{Statistical analysis}

For the reliability analysis of the MRI scoring, we used Kappa statistics. Agreement strengths for the Kappa values were classified according to Landis and Koch [22]. For the comparison of the outcome in patients with different MRI characteristics, we used nonparametric tests (Kruskal-Walis test for group comparison; post hoc analysis was performed using the Mann-Whitney test when the level of significance was reached). Correlations were assessed with the Spearman's rank correlation coefficient. For the statistical analysis, we used SPSS $^{\circledR}$ version 14.0 for Windows. Level of significance was set at 0.05 .

\section{Results}

\section{Clinical characteristics and level of functioning}

Thirty-six patients underwent SDR of whom 32 patients had a brain MRI performed before SDR, and 26 MRIs were available for review. Of the patients with available MRI, four did not have any preoperative GMFM-66 assessments. Three patients had a GMFM-66 assessment before SDR but with a follow-up period of less than 12 months. The detailed patient characteristics of the remaining 19 patients are summarized in Table 2. The mean number of GMFM assessments per patient was 4.9 (standard deviation (SD) 3.5 , range 1 to 12 ), and the mean follow-up period was 5 years and 4 months (SD 2 years and 9 months, range 1 year and 1 month to 9 years). The mean age at the time of the operation was 6 years and 10 months (SD 1 year and 6 months, range 5 years and 9 months to 10 years and1 month). The age at the time of SDR neither correlate with the preoperative GMFM-66 (rho, $0.328 ; p=0.184$ ) nor with the postoperative GMFM-66 scores (rho, 0.336; $p=$ 0.173 ) and the improvement after SDR (rho, $-0.049 ; p=$ 0.847). We found no difference in the Delta-GMFM-66 score between boys and girls. 

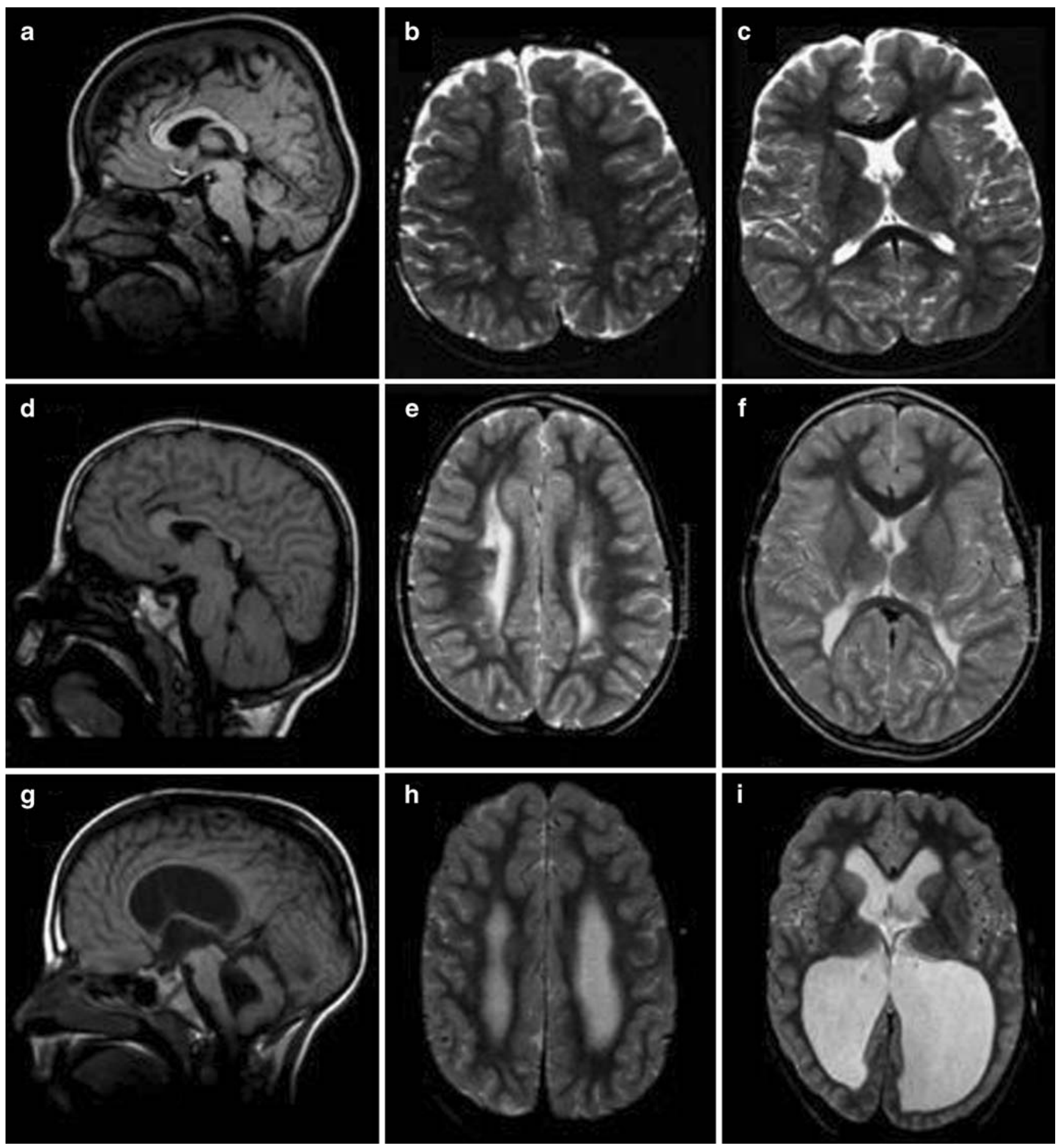

Fig. 1 a-i MR imaging of three patients with bilateral spastic paresis undergoing SDR. a, d, g Midsagittal T1 weighted images. b, e, h Transversal T2 weighted images at the level of the centrum semiovale. g, h, i Transversal T2 weighted imaging at the level of the basal ganglia. a-c MR images classified as "normal." $\mathbf{d}-\mathbf{f}$ MR images classified as periventricular leucomalacia showing thinning of the corpus callosum involving the total body (Fig. 1a), bilaterally increased periventricular white matter signal intensity (Fig. 1e), a slight ventricular enlargement, and a loss of the occipital white matter (Fig. 1f). g-i MR images classified as hydrocephalus. The lateral ventricles and the third and fourth ventricles (Fig. 1i) are enlarged 
Table 2 Summary of the characteristics of the patients included in the study

\begin{tabular}{|c|c|c|c|c|c|c|c|c|c|}
\hline Case & Gender & GA (weeks) & BW (g) & $\begin{array}{l}\text { Age SDR } \\
\text { years (mts) }\end{array}$ & $\begin{array}{l}\text { Follow-up } \\
\text { years (mts) }\end{array}$ & $\begin{array}{l}\text { MRI } \\
\text { classification }\end{array}$ & Diagnosis & $\begin{array}{l}\text { GMFM-66 } \\
\text { before SDR }\end{array}$ & $\begin{array}{l}\text { GMFM-66 } \\
\text { (mean) } \\
\text { after SDR }\end{array}$ \\
\hline 1 & $\mathrm{~F}$ & 30 & 2,000 & $5(7)$ & $8(5)$ & PVL & PVL & 50.85 & 53.29 \\
\hline 2 & $\mathrm{~F}$ & 40 & 2,500 & $5(7)$ & $9(0)$ & PVL & PVL & 47.68 & 49.66 \\
\hline 3 & $\mathrm{~F}$ & 40 & 3,450 & $5(8)$ & $8(11)$ & PVL & PVL & 54.38 & 55.71 \\
\hline 4 & M & 30 & 1,650 & $6(8)$ & $8(11)$ & PVL & PVL & 46.91 & 48.32 \\
\hline 5 & $\mathrm{~F}$ & 28 & 1,285 & $4(11)$ & $7(10)$ & PVL & PVL & 50.32 & 54.75 \\
\hline 6 & M & 26 & 1,000 & $5(3)$ & $7(10)$ & PVL & PVL & 64.98 & 67.82 \\
\hline 7 & M & 32 & 2,510 & $5(1)$ & $6(7)$ & PVL & PVL & 54.15 & 60.38 \\
\hline 8 & M & 33 & 1,265 & $8(9)$ & $5(1)$ & PVL & PVL & 47.09 & 55.92 \\
\hline 9 & M & 26 & 870 & $6(11)$ & $3(11)$ & PVL & PVL & 50.09 & 54.32 \\
\hline 10 & M & 26 & 780 & $5(4)$ & $3(0)$ & PVL & PVL & 52.32 & 62.98 \\
\hline 11 & $\mathrm{~F}$ & 41 & 3,060 & $8(4)$ & $5(2)$ & Hydrocephalus & Congenital hydrocephalus & 55.62 & 56.35 \\
\hline 12 & M & 27 & 1,020 & $10(1)$ & $4(5)$ & Hydrocephalus & Congenital hydrocephalus & 68.86 & 68.69 \\
\hline 13 & M & 40 & 3,300 & $5(9)$ & $7(2)$ & Normal & Unknown & 65.33 & 67.31 \\
\hline 14 & M & 34 & 3,155 & $6(11)$ & $3(0)$ & Normal & Spinal process & 76.75 & 85.15 \\
\hline 15 & M & 38 & 4,280 & $8(0)$ & $2(7)$ & Normal & Unknown & 82.99 & 89.70 \\
\hline 16 & $\mathrm{~F}$ & 40 & 3,875 & $8(10)$ & $1(7)$ & Normal & HIV-Encephalo(myelo)pathy & 73.63 & 80.46 \\
\hline 17 & M & 39 & 4,040 & $6(7)$ & $2(0)$ & Normal & Unknown & 65.98 & 78.38 \\
\hline 18 & M & 40 & 3,460 & $6(5)$ & $1(1)$ & Normal & Unknown & 73.63 & 81.93 \\
\hline 19 & M & 37 & 3,400 & $3(11)$ & $7(1)$ & Not classified & Laurence moon syndrome & 47.26 & 83.01 \\
\hline
\end{tabular}

$F$ female, $M$ male, $G A$ gestational age, $B W$ birth weight, $S D R$ selective dorsal rhizotomy, GMFCS gross motor function classification system, GMFM gross motor function measure, $P V L$ periventricular leucomalacia, $g$ gram, $m t s$ months

\section{Neuroimaging}

We diagnosed PVL in ten patients, hydrocephalus in two patients, and no MRI abnormalities in six patients. The classification of MRIs did not differ between the two observers. With respect to the grading of the MR abnormalities, the intrarater agreement was perfect for the frontal and occipital white matter loss, cysts, thinning of the corpus callosum, subarachnoidal space, and gray matter abnormalities (Kappa, 1.0) and almost perfect for the ventricular size (Kappa, 0.90) and the white matter signal intensities (Kappa, 0.87). The interrater agreement was considerably less than the intrarater agreement. It was perfect for the subarachnoidal space and the gray matter abnormalities (Kappa, 1.0), almost perfect for the ventricular size (Kappa, 0.90), substantial for the occipital white matter loss (Kappa, 0.74), and moderate for the frontal white matter loss (Kappa, 0.45). Kappa statistics

Table 3 Differences of gross motor outcome in with patients with different MRI classification

\begin{tabular}{|c|c|c|c|c|c|c|c|c|c|c|c|c|c|}
\hline & \multicolumn{3}{|c|}{ Normal MRI $(n=6)$} & \multicolumn{3}{|c|}{ PVL $(n=10)$} & \multicolumn{3}{|c|}{ Hydrocephalus $(n=2)$} & \multicolumn{3}{|c|}{ Total $(n=18)$} & \multirow[t]{2}{*}{$P$ value } \\
\hline & Mean & $\mathrm{SD}$ & Range & Mean & $\mathrm{SD}$ & Range & Mean & SD & Range & Mean & $\mathrm{SD}$ & Range & \\
\hline GMFM-66 before SDR & $73.1^{\mathrm{a}}$ & 6.7 & $65.3-83.0$ & $51.9^{\mathrm{a}}$ & 5.3 & $46.9-65.0$ & 62.2 & 9.4 & $55.6-68.9$ & 60.1 & 11.5 & $46.9-83.0$ & 0.002 \\
\hline Mean GMFM-66 after SDR & $80.5^{\mathrm{a}}$ & 7.6 & $67.3-89.7$ & $56.3^{\mathrm{a}}$ & 5.9 & $48.3-67.8$ & 62.5 & 8.7 & $56.3-68.7$ & 65.1 & 13.0 & $48.3-89.7$ & 0.003 \\
\hline Delta-GMFM-66 & $7.4^{\mathrm{b}}$ & 3.4 & $2.0-12.4$ & $4.4^{\mathrm{c}}$ & 3.2 & $1.3-10.7$ & $0.3^{\mathrm{b}, \mathrm{c}}$ & 0.6 & $-0.2-0.7$ & 5.0 & 3.7 & $-0.2-12.4$ & 0.030 \\
\hline
\end{tabular}

MRI magnetic resonance imaging, $P V L$ periventricular leucomalacia, $S D$ standard deviation, GMFM gross motor function measure

${ }^{\text {a }}$ Significant difference with $p<0.05$ (Mann-Whitney test) between normal MRI and PVL

${ }^{\mathrm{b}}$ Significant difference with $p<0.05$ (Mann-Whitney test) between normal MRI and Hydrocephalus

${ }^{\mathrm{c}}$ Significant difference with $p<0.05$ (Mann-Whitney test) between hydrocephalus and PVL 


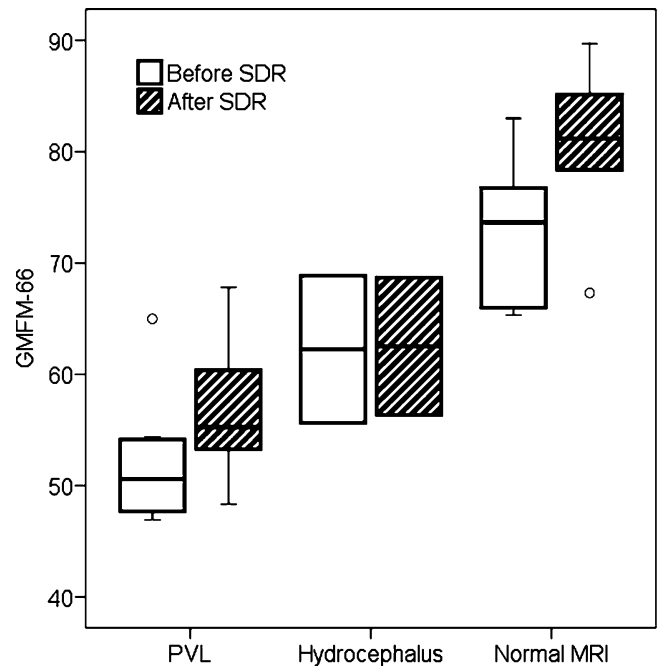

Fig. 2 Box plots of the preoperative GMFM-66 (white boxes) and the mean values of all postoperative GMFM-66 measurements (dashed boxes) in patients with different MRI classification. Note that the largest improvements after SDR were observed in patients with normal MRI and that the patients with hydrocephalus did not improve after SDR

could not be calculated for the white matter signal intensities, cysts, and thinning of the corpus callosum as only one of the two observers graded severe abnormalities (according grade three on the point scale). With respect to the white matter signal intensities and the thinning of the corpus callosum, the observers disagreed in $25 \%$ of the scorings, with respect to the cysts there was a disagreement in $36 \%$.

The outcome parameters in patients with different MRI classification are summarized in Table 3 and in Fig. 2. The preoperative GMFM-66 scores were significantly higher in patients with normal MRI than in patients with PVL ( $p=$ 0.001). Patients with hydrocephalus had intermediate scores and did not differ significantly from the other groups. In the follow-up measurements, the mean GMFM-66 was the highest in patients with a normal MRI (group difference, $p=$ 0.003; difference between PVL and normal, $p=0.002$ ). The patients with normal MRI also made the best postoperative improvements. Almost no improvement was observed in the patients with hydrocephalus (group difference $p=0.030$; difference between PVL and hydrocephalus, $p=0.032$; difference between hydrocephalus and normal MRI, $p=$ 0.046 ). There was a significant group difference in age at the time of the operation $(p=0.028)$. Patients with normal MRI and patients with hydrocephalus were older at the time of the operation than patients with PVL-for the patients with normal MRI this difference was significant $(p=0.044)$.

The scoring of the MRI abnormalities in the patients with PVL is summarized in Table 4. Two patients with PVL did not show ventricular enlargement, and eight patients had moderate ventricular enlargement. All patients had moderate white matter signal intensity. Nine patients had moderate occipital white matter loss, and one patient had moderate frontal white matter loss. Small cysts were found in one patient, and large cysts were found in two. Four patients had no thinning of the corpus callosum, and six patients had moderate thinning of the corpus callosum. None of the patients had gray matter abnormalities or an enlargement of the subarachnoidal space. The mean total score was 10.8 (SD, 1.1; range, 8 to 12). The total score did not correlate with any of the outcome parameters. The ventricular size showed a significant correlation with the preoperative GMFM-66 score (rho, $-0.696 ; p=0.025$ ). However, none of the items in the scoring correlated with the postoperative changes of the GMFM- 66 .

\section{Discussion}

The aim of this study was to identify possible relationships between MR characteristics and the level of functioning before and after SDR in patients with bilateral spastic paresis. We classified the MRIs in three MRI categories: PVL, hydrocephalus, and normal MRI and compared the postoperative improvement in the GMFM in the three groups. The best results were found in the group with normal MRI, and the poorest results were found in patients with hydrocephalus. The poor outcome of patients with
Table 4 Scoring of the MR abnormalities in patients with periventricular leucomalacia $(n=10)$

\begin{tabular}{llcl}
\hline & Normal & Moderate & Severe \\
\hline Ventricular size & $2(20 \%)$ & $8(80 \%)$ & $0(0 \%)$ \\
White matter signal intensity & $0(0 \%)$ & $10(100 \%)$ & $0(0 \%)$ \\
White matter loss & $1(10 \%)$ & $9(90 \%)$ & $0(0 \%)$ \\
Thinning of the corpus callosum & $4(40 \%)$ & $6(60 \%)$ & $0(0 \%)$ \\
Cysts & $7(70 \%)$ & $1(10 \%)$ & $2(20 \%)$ \\
Gray matter abnormality & $10(100 \%)$ & $0(0 \%)$ & $0(0 \%)$ \\
Enlargement of the subarachnoidal space & $10(100 \%)$ & $0(0 \%)$ & $0(0 \%)$ \\
& Mean & $\mathrm{SD}$ & Range \\
Total Score & 10.8 & 1.1 & $8-12$ \\
\hline
\end{tabular}


hydrocephalus could be a consequence of persistently elevated intracranial pressure, which can be observed in the absence of characteristic symptoms in children with $\mathrm{CP}$ [23]. In the present study, both patients with hydrocephalus (patient 11 and patient 12) underwent surgical correction. Patient 11 had a ventriculo peritoneal shunt placed early during childhood. Patient 12 was diagnosed with hydrocephalus a few months before SDR, and he underwent third ventriculostomy. Unfortunately, there was no follow-up imaging available for either of these patients, and although neither of them showed any clinical evidence of elevated intracranial pressure, it cannot be ruled out definitively. Previous studies found greater postoperative improvements after SDR in children with less motor impairment [7, 13]. In contrast, in the three randomized controlled trials comparing functional outcome after SDR, the poorest results were found in the study which included children with the best preoperative gross motor skills $[9,10]$. In the present study, the patients with normal MRI had much better preoperative gross motor skills than the patients with PVL and hydrocephalus. We found no correlation between the preoperative GMFM score and its improvement postoperatively. McLaughlin et al. found an inverse correlation between the age at the time of the operation and the postoperative changes in the GMFM [9]. This could be explained as a consequence of faster spontaneous motor development in early childhood. However, in our study, not only the children with hydrocephalus (who showed the poorest outcome), but also the children with normal MRI (who showed the best outcome) were older than the patients with PVL when SDR was performed. There was no correlation between the age at the time of SDR and outcome.

In the patients with PVL, we graded the severity of the MR abnormalities and correlated them with the gross motor abilities. For this purpose, we used a grading scale that has previously been used to describe MR abnormalities in patients with spastic CP $[20,24]$. We performed a reliability analysis of the various items included in this grading scale. The agreement between investigators was substantially worse than in the Cioni et al. study in which two experienced raters scored the MRIs [20]. In the present study, the interobserver reliability was notably poor for the assessment of the cysts. Several explanations should be considered: it was difficult to detect cysts in an area with extensive gliosis, there is a difference between the level of experience with brain MRI in the two investigators ( 2 years vs 8 years). Only the amount of ventricular enlargement correlated with the preoperative gross motor abilities. Correlations between ventricular size and gross motor abilities have been described previously in patients with spastic CP [25]. In contrast to the findings of previous studies $[20,24,26]$, we did not find a correlation between gross motor skills and the total MRI score/the thinning of the corpus callosum. However, the present study was limited to ambulatory patients with GMFCS levels I to III, and patients with more severe motor handicaps where more severe brain abnormalities could be expected on MRI have not been studied. No correlations were found between the severity of the brain anomalies and the outcome after SDR.

The outcome assessment in the present study consisted in the GMFM-66 which-according to the International Classification of Functioning, Disability, and Healths (ICF) [27] — assesses the domain of activity. However, the other two domains of the ICF - body structure and participationhave not been evaluated. One other limitation of the present study was the small sample size. Unfortunately, we did not have access to all MRI scans and not all patients had a preoperative GMFM assessment. We could only include data on a small number of patients in our analysis. Notably, the group with hydrocephalus was small and comprised only two patients. Therefore, the association between the type of brain lesion and the outcome after SDR needs to be proved in future studies with larger study samples, including the other ICF domains - body structure and participation.

\section{Conclusion}

We found significant differences in the post-operative changes in the GMFM-66 in patients with different brain MRI abnormalities. The largest postoperative improvement was observed in patients with normal MRI, and the poorest outcome was observed in patients with hydrocephalus. In patients with PVL, we could not detect any relation between MRI abnormalities and the postoperative improvement in of gross motor function after SDR. We conclude that MRI of the brain can provide additional information for the selection of patients for SDR. However, the degree of PVL does not provide information about the degree of improvement in gross motor function after SDR.

Acknowledgment We are very grateful to Mrs. Maaike Schothorst, who motivated the parents and the children to participate and collected the patient data. We also wish to thank Dr. R. Strijers who performed all electrophysiological measurements during the interventions.

Open Access This article is distributed under the terms of the Creative Commons Attribution Noncommercial License which permits any noncommercial use, distribution, and reproduction in any medium, provided the original author(s) and source are credited.

\section{References}

1. Lance JW (1980) Symposium synopsis. In: Feldman RG, Young RR, Keolla WP (eds) Spasticity: disorder of motor control. Yearbook Medical, Chicago, pp 485-494 
2. Rosenbaum P, Paneth N, Leviton A, Goldstein M, Bax M, Damiano D, Dan B, Jacobsson B (2007) A report: the definition and classification of cerebral palsy April 2006. Dev Med Child Neurol 109:8-14

3. Abel MF, Damiano DL, Gilgannon M, Carmines D, Kang HG, Bennett BC, Laws ER Jr (2005) Biomechanical changes in gait following selective dorsal rhizotomy. J Neurosurg 102:157-162

4. Langerak NG, Lamberts RP, Fieggen AG, Peter JC, van der Merwe L, Peacock WJ, Vaughan CL (2008) A prospective gait analysis study in patients with diplegic cerebral palsy 20 years after selective dorsal rhizotomy. J Neurosurg Pediatr 3:180-186

5. Trost JP, Schwartz MH, Krach LE, Dunn ME, Novacheck TF (2008) Comprehensive short-term outcome assessment of selective dorsal rhizotomy. Dev Med Child Neurol 50:765-771

6. Steinbok P (2001) Outcomes after selective dorsal rhizotomy for spastic cerebral palsy. Childs Nerv Syst 17:1-18

7. Nordmark E, Josenby AL, Lagergren J, Andersson G, Strömblad LG, Westbom L (2008) Long-term outcomes five years after selective dorsal rhizotomy. BMC Pediatr 8:54

8. van Schie PE, Vermeulen RJ, van Ouwerkerk WJ, Kwakkel G, Becher JG (2005) Selective dorsal rhizotomy in cerebral palsy to improve functional abilities: evaluation of criteria for selection. Childs Nerv Syst 21:451-457

9. McLaughlin JF, Bjornson KF, Astley SJ, Graubert C, Hays RM, Roberts TS, Price R, Temkin N (1998) Selective dorsal rhizotomy: efficacy and safety in an investigator-masked randomized clinical trial. Dev Med Child Neurol 40:220-232

10. McLaughlin J, Bjornson K, Temkin N, Steinbok P, Wright V, Reiner A, Roberts T, Drake J, O'Donnell M, Rosenbaum P, Barber J, Ferrel A (2002) Selective dorsal rhizotomy: meta-analysis of three randomized controlled trials. Dev Med Child Neurol 44:17-25

11. Wright FV, Sheil EM, Drake JM, Wedge JH, Naumann S (1998) Evaluation of selective dorsal rhizotomy for the reduction of spasticity in cerebral palsy: a randomized controlled trial. Dev Med Child Neurol 40:239-247

12. Steinbok P, Reiner AM, Beauchamp R, Armstrong RW, Cochrane DD, Kestle J (1997) A randomized clinical trial to compare selective posterior rhizotomy plus physiotherapy with physiotherapy alone in children with spastic diplegic cerebral palsy. Dev Med Child Neurol 39:178-184

13. Mittal S, Farmer JP, Al-Atassi B, Gibis J, Kennedy E, Galli C, Courchesnes G, Poulin C, Cantin MA, Benaroch TE (2002) Longterm functional outcome after selective posterior rhizotomy. J Neurosurg 97:315-325

14. Grunt S, van der Knaap MS, Ouwerkerk WRJ, Strijers RLM, Becher JG, Vermeulen RJ (2008) Effectiveness of selective dorsal rhizotomy in two patients with progressive spasticity due to neurodegenerative disease. J Child Neur 23:818-822

15. Ashwal S, Russman BS, Blasco PA, Miller G, Sandler A, Shevell M, Stevenson R (2004) Practice parameter: diagnostic assessment of the child with cerebral palsy: report of the quality standards subcommittee of the American academy of neurology and the practice committee of the child neurology society. Neurology 62:851-863

16. Bax M, Tydeman C, Flodmark O (2006) Clinical and MRI correlates of cerebral palsy: the European cerebral palsy study. JAMA 296:1602-1608

17. Krageloh-Mann I, Horber V (2007) The role of magnetic resonance imaging in elucidating the pathogenesis of cerebral palsy: a systematic review. Dev Med Child Neurol 49:144-151

18. Robinson MN, Peake LJ, Ditchfield MR, Reid SM, Lanigan A, Reddihough DS (2009) Magnetic resonance imaging findings in a population-based cohort of children with cerebral palsy. Dev Med Child Neurol 51:39-45

19. Korzeniewski SJ, Birbeck G, DeLano MC, Potchen MJ, Paneth N (2008) A systematic review of neuroimaging for cerebral palsy. J Child Neurol 23:216-227

20. Cioni G, Di Paco MC, Bertuccelli B, Paolicelli PB, Canapicchi R (1997) MRI findings and sensorimotor development in infants with bilateral spastic cerebral palsy. Brain Dev 19:245-253

21. Russell DJ, Rosenbaum PL, Cadman DT, Gowland C, Hardy S, Jarvis S (1989) The gross motor function measure: a means to evaluate the effects of physical therapy. Dev Med Child Neurol 31:341-352

22. Landis JR, Koch GG (1977) The measurement of observer agreement for categorical data. Biometrics 33:159-174

23. Albright AL, Ferson S, Carlos S (2005) Occult hydrocephalus in children with cerebral palsy. Neurosurgery 56:93-96

24. Kułak W, Sobaniec W, Kubas B, Walecki J, Smigielska-Kuzia J, Bockowski L, Artemowicz B, Sendrowski K (2007) Spastic cerebral palsy: clinical magnetic resonance imaging correlation of 129 children. J Child Neurol 22:8-14

25. Melhem ER, Hoon AH Jr, Ferrucci JT Jr, Quinn CB, Reinhardt EM, Demetrides SW, Freeman BM, Johnston MV (2000) Periventricular leukomalacia: relationship between lateral ventricular volume on brain MR images and severity of cognitive and motor impairment. Radiology 214:199-204

26. Kulak W, Sobaniec W, Kubas B, Walecki J (2007) Corpus callosum size in children with spastic cerebral palsy: relationship to clinical outcome. J Child Neurol 22:371-374

27. World Health Organisation (2001) International classification of functioning, disability and health (ICF). WHO, Geneva 